\title{
Study of PVDF/ (Co-ZnFe2O4 and Cu-ZnFe204) nanocomposite for the piezo-phototronics applications
}

Mai EL-Masry ( $\sim$ mai.elmasry@thebes.edu.eg)

Higher Engineering Institute https://orcid.org/0000-0002-2681-0883

Rania Ramadan

Cairo University

\section{Research Article}

Keywords: Piezoelectric, PVDF, Copper doped Zinc ferrite, cobalt doped Zinc ferrite, dielectric constant, optical conductivity, nonlinear susceptibility

Posted Date: January 3rd, 2022

DOI: https://doi.org/10.21203/rs.3.rs-853775/v2

License: (c) (1) This work is licensed under a Creative Commons Attribution 4.0 International License.

Read Full License

Version of Record: A version of this preprint was published at Applied Physics A on January 12th, 2022. See the published version at https://doi.org/10.1007/s00339-021-05238-6. 


\title{
Study of $\mathrm{PVDF} /\left(\mathrm{Co}-\mathrm{ZnFe}_{2} \mathrm{O}_{4}\right.$ and $\left.\mathrm{Cu}-\mathrm{ZnFe}_{2} \mathrm{O}_{4}\right)$ nanocomposite for the piezo-phototronics applications
}

\author{
Mai M. El-Masry ${ }^{(\mathrm{a}) *}$, Abdelmoty M. Ahmed ${ }^{(\mathrm{b})}$ and Rania Ramadan ${ }^{(\mathrm{c}) * *}$ \\ ${ }^{a}$ Basic Science Dept., Higher Engineering Institute, Thebes Academy, Cairo, Egypt, \\ ${ }^{b}$ Department of Computer Engineering, College of Computer Science, King Khalid \\ University, Saudi Arabia \\ ${ }^{\mathrm{c}}$ Materials Science Lab. (1), Physics Department, Faculty of Science, Cairo University, \\ Giza, Egypt
}

\begin{abstract}
Polyvinylidene fluoride (PVDF) polymer is considered as a promising piezoelectric material whose optical properties need to be improved. Zinc ferrite is an excellent photoelectric material, in the present work it was doped separately by both cobalt and copper. $\mathrm{Co}-\mathrm{ZnFe}_{2} \mathrm{O}_{4}$ and $\mathrm{Cu}-\mathrm{ZnFe} \mathrm{O}_{4}$ nanoparticles were synthesized and characterized to be used as PVDF fillers, aiming to improve its optical properties. The optical properties as well as, the piezoelectric response of the prepared PVDF/ $\left(\mathrm{Co}-\mathrm{ZnFe}_{2} \mathrm{O}_{4}\right.$ and $\mathrm{Cu}-\mathrm{ZnFe}_{2} \mathrm{O}_{4}$ ) nanocomposites were investigated. A remarkable improvement in the PVDF relative permittivity, optical conductivity, refractive index, non-linear susceptibility, and a great reduction in the band gap energy value is obtained by adding $\mathrm{Co}-\mathrm{ZnFe}_{2} \mathrm{O}_{4}$ nanoparticles to it. However, $\mathrm{Cu}-\mathrm{ZnFe}_{2} \mathrm{O}_{4}$ nanoparticles have limited improvement of the PVDF optical properties compared to the $\mathrm{Co}-\mathrm{ZnFe}_{2} \mathrm{O}_{4}$ nanoparticles. The piezoelectric response of the PVDF polymer is clearly increased by the addition of both $\mathrm{Co}-\mathrm{ZnFe} 2 \mathrm{O}_{4}$ and $\mathrm{Cu}-\mathrm{ZnFe}_{2} \mathrm{O}_{4}$ nanoparticles.
\end{abstract}

Keywords: Piezoelectric; PVDF; Copper doped Zinc ferrite; cobalt doped Zinc ferrite; dielectric constant; optical conductivity; nonlinear susceptibility.

Correspondence: * mai.elmasry@thebes.edu.eg (Mai M. El-Masry); **rramadan@sci.cu.edu.eg (Rania Ramadan). 


\section{Introduction}

In the last decades there is a potential support for using renewable energy, for its economic, environmentally friendly properties [1], [2]. Energy harvesting from mechanical energy (piezo electricity) become very influential lately. Piezoelectricity is produced due to the spontaneous separation of charge within crystal structures in certain conditions. A displacement of the electron relative to their atomic centers, referred to an electric polarization produced by the application of mechanical stress along the appropriate direction of a crystal however, an applied electric field can generate a mechanical distortion in the material. The phenomenon of Piezoelectricity can be used in many applications, including sensors and actuator applications. [3].

Ceramic piezoelectric materials have a great role in the field of sensors [4]. Although these materials have large relative permittivity, facilitate electrical tuning, they are tainted by defects such as low inherent breakdown strength, these materials are brittle which limiting their applications in flexible or wearable devices.

Polyvinylidene fluoride (PVDF) polymer is a good alternative for ceramic materials. It is possessing unique advantages over ceramic such as flexibility, further, PVDF is inert chemically, it has electroactive $\beta$-polymorphic phase with great toughness and small fatigue failure can produce remarkable voltage under long-term continuous oscillations. However, PVDF has the disadvantage of low dielectric permittivity. Coupling between polymer and ceramic fillers nanoparticles gives a composite material with new properties. This modification related to insitu growth of $\beta$-crystalline phase within the nanocomposites which improve the dielectric and energy harvesting performance of the nanocomposite [5] [6] [7]. The increase in dipole-dipole interaction with the increase of the filler content leads to higher dielectric constant composite material. [8], [6]. [9]. 
A lot of attention has been paid to the Piezoelectric semiconductor nanomaterials for its excellent properties Combines the excellent properties of nanomaterials and the strength of polymers. Recently the need for further research in the field of piezotronics and piezo-phototronics increased, where charge-carrier transport is controlled by the application of external mechanical stimuli in flexible devices [10]. The fundamental investigations of piezoelectricity and semiconductor properties utilizing useful nanomaterials prompts the improvement of more intelligent electronics and optoelectronics materials. [11].

In the present study, $\mathrm{Co}-\mathrm{ZnFe} 2 \mathrm{O}_{4}$ and $\mathrm{Cu}-\mathrm{ZnFe}_{2} \mathrm{O}_{4}$ have been investigated as PVDF nanofillers, where $\mathrm{Co}-\mathrm{ZnFe} 2 \mathrm{O}_{4}$ and $\mathrm{Cu}-\mathrm{ZnFe}_{2} \mathrm{O}_{4}$ are reported as semiconductor materials [12], [13]. The investigated nanocomposites were prepared using simple solution casting method [14] The PVDF polymer has dissolved in dimethyl formamide (NMP), $\mathrm{Co}-\mathrm{ZnFe}_{2} \mathrm{O}_{4}$ and $\mathrm{Cu}-\mathrm{ZnFe} 2 \mathrm{O} 4$ nanoparticles are synthesized, characterized, and introduced into the solution as the PVDF nanofiller. The effect of $\mathrm{Co}-\mathrm{ZnFe}{ }_{2} \mathrm{O}_{4}$ compared to $\mathrm{Cu}-\mathrm{ZnFe}_{2} \mathrm{O}_{4}$ on the PVDF optical properties and piezoelectric response were investigated. The present work aims to study the piezoelectric and optoelectronic properties of PVDF /(Co- $\mathrm{ZnFe}_{2} \mathrm{O}_{4}$ and $\left.\mathrm{Cu}-\mathrm{ZnFe} 2 \mathrm{O}_{4}\right)$.

\section{Materials and Methods}

\subsection{Materials}

Poly (vinylidene fluoride) (PVDF) powder (Sigma Aldrich, USA), and N-Methyl-2-Pyrrolidone (NMP, $99.5 \%$ of purity) (Merk Chemical, India), iron nitrate $\mathrm{Fe}\left(\mathrm{NO}_{3}\right) 3 \cdot 9 \mathrm{H}_{2} \mathrm{O}(99 \%)$, cobalt nitrate $\mathrm{Co}\left(\mathrm{NO}_{3}\right)_{2} \cdot 6 \mathrm{H}_{2} \mathrm{O}$, copper nitrate $\mathrm{Cu}\left(\mathrm{NO}_{3}\right)_{2} \cdot 6 \mathrm{H}_{2} \mathrm{O}(99 \%)$, zinc nitrate $\left[\mathrm{Zn}\left(\mathrm{NO}_{3}\right)_{2} \cdot 6 \mathrm{H}_{2} \mathrm{O}\right]$ and citric acid $\left(\mathrm{C}_{6} \mathrm{H}_{8} \mathrm{O}_{7}\right)$, were used as raw materials.

\subsection{Sample's preparation methods}

\subsubsection{Nano powder preparation}


Citrate auto-combustion method has been used to synthesize $\mathrm{Co}-\mathrm{ZnFe}_{2} \mathrm{O}_{4}$ and $\mathrm{Cu}-\mathrm{Zn} \mathrm{Fe}_{2} \mathrm{O}_{4}$ nanoparticles. A stoichiometric ratio of cobalt nitrate, copper nitrate, zinc nitrate, iron nitrate and citric acid were dissolved in a small amount of distilled water and a vigorous stirring was applied to the solution. The $\mathrm{pH}$ of the solution was adjusted at 7 . The solution temperature was raised up to $250^{\circ} \mathrm{C}$ to obtain a fine powder. The obtained powder was calcined for $4 \mathrm{~h}$ at $800{ }^{\circ} \mathrm{C}$ with rate of $4{ }^{\circ} \mathrm{C} / \mathrm{min}$.

\subsection{2. ( $\mathrm{PVDF} / \mathrm{Co}-\mathrm{ZnFe}_{2} \mathrm{O}_{4}$ and $\mathrm{Cu}-\mathrm{Zn} \mathrm{Fe}_{2} \mathrm{O}_{4}$ ) film preparation}

A transparent solution of (PVDF/NMP) was obtained by dissolving 3gm. of PVDF powder in $10 \mathrm{~mL}$. of (NMP) at room temperature under continuous stirring. To prepare the nanocomposite films 3 milligrams of the $\mathrm{Co}-\mathrm{ZnFe}_{2} \mathrm{O}_{4}$ and $\mathrm{Cu}-\mathrm{Zn} \mathrm{Fe}_{2} \mathrm{O}_{4}$ nanoparticles were dissolved in appropriate amount of (NMP) and vigorous stirring was applied, the obtained solution were added to the (PVDF/NMP) solution and sonicated for $2 \mathrm{~h}$. Finally, each sample was poured on a clean glass surface on a hotplate kept at $60^{\circ} \mathrm{C}$. The obtained films of about $(50 \times 50 \times 0.16 \mathrm{~mm})$ washed using distilled water to remove any contaminating particles and for full solidification of the films.

\subsection{Characterization of nanoparticles}

The crystalline phases of $\mathrm{Co}-\mathrm{ZnFe} 2 \mathrm{O}_{4}$ and $\mathrm{Cu}-\mathrm{Zn} \mathrm{Fe} \mathrm{O}_{4}$ nanoparticles were identified by Fourier Transform Infrared Spectroscopy instrument (FT-IR) (Perkin Elmer) in the range of 4000-400 $\mathrm{cm}^{-1}$. The degree of crystallinity was investigated using, X-ray diffraction (XRD) analysis (Bruker, $\mathrm{D}_{8}$ Advance, $\mathrm{X}$-ray diffractometer), operating at $40 \mathrm{kV}$ and current $40 \mathrm{~mA}$ with $\mathrm{Cu}-\mathrm{Ka}$ radiation $(1=1.541 \AA$ ). Transmission Electron Microscope (HRTEM) JEM-ARM300F operating at $200 \mathrm{kV}$ was used for topographical investigation of the prepared nanoparticles.

\subsection{Optical properties investigation}


UV-vis spectra of the prepared nanocomposite films obtained using (JASCO Corp., V-570, Rev. 1.00)

\subsection{Piezoelectric response}

\subsubsection{Digital storage oscilloscope}

The generated voltage by repeating human finger press and release on the surface of the investigated nanocomposite films has been recorded using a digital storage oscilloscope [GW Instek Gos-806s]. The responses were recorded in terms of open circuit output voltage, at room temperature.

\subsubsection{Piezo response Force Microscopy (PFM)}

Flex-Axiom AFM was used for measuring the piezo response force. The specifications of the PFM are commercial head type with 115-135 $\mu \mathrm{m}$ length, Co-Cr coated tip with electrical resistivity of $0.01-0.025 \Omega \cdot \mathrm{cm}$ with nearly $35 \mathrm{~nm}$ tip curvature nominal spring constant of $5 \mathrm{~N} / \mathrm{m}$ and165.08kHz nominal resonance frequency. A.c. voltage was applied to the tip, at a frequency of $165.08 \mathrm{kHz}$ for measuring the piezoresponse of samples. Scan rate was $0.5 \mathrm{~Hz}$ while the scan area was $(250 \times 250) \mathrm{nm}^{2}$. Insulating chamber is used for all measurements at room temperature.

\section{Results}

\subsection{Nanoparticles characterization}

\subsubsection{XRD}

Figure 1 illustrate the XRD patterns of the synthesized $\mathrm{Co}-\mathrm{ZnFe} \mathrm{O}_{4}$ and $\mathrm{Cu}-\mathrm{Zn} \mathrm{Fe} 2 \mathrm{O}_{4}$ powder. From the figure it can be noted the formation of single-phase cubic spinel and cubic structures for $\mathrm{Co}-\mathrm{ZnFe} \mathrm{O}_{4}$ and $\mathrm{Cu}-\mathrm{Zn} \mathrm{Fe}_{2} \mathrm{O}_{4}$ samples respectively. The spectrum shown in the figure confirms that the obtained patterns match well the reported standard phase in the XRD reference 
ICDD cards: [04-002-0421] and [01-077-0013] for Zinc Iron Cobalt Oxide and Copper Zinc Iron Oxide respectively. Few peaks appeared in the pattern which corresponding to Hematite, that is compatible with the ICDD card [00-024-0072]. The particles sizes of the prepared nanoparticles were calculated using Scherrer's equation [15]

$D=\frac{k \lambda}{\beta \cos \theta}$,

Where, $\mathrm{D}$ is the crystallite size $(\mathrm{nm}), \mathrm{K}$ is the particle shape factor $(0.9), \lambda$ is the target wavelength $(\mathrm{nm}), \beta$ is the corrected full width at half maximum, and $\theta$ is the position (angle) at the maximum of the peak at. The estimated particle sizes are $28.8 \mathrm{~nm}$ and $35.8 \mathrm{~nm}$. for the $\mathrm{Co}-\mathrm{ZnFe} 2 \mathrm{O} 4$ and $\mathrm{Cu}-\mathrm{Zn} \mathrm{Fe} 2 \mathrm{O} 4$ nanoparticles, respectively.

\subsubsection{FTIR}

The FTIR spectra in the range 4000-400 cm-1of $\mathrm{Co}-\mathrm{ZnFe}_{2} \mathrm{O}_{4}$ and $\mathrm{Cu}-\mathrm{Zn} \mathrm{Fe}_{2} \mathrm{O}_{4}$ nanoparticles are shown in Figure 2. The bands located at $2900-2997 \mathrm{~cm}^{-1}$ attributed to the O-H stretching bond existing in the adsorbed water molecules. The peaks corresponding to $1117 \mathrm{~cm}^{-1}$ band is attributed to the Fe-Co alloy system [16] [17]. Bands present at $535-533 \mathrm{~cm}^{-1}$ belongs to hematite phases. [18]. $430 \mathrm{~cm}^{-1}$ and $412 \mathrm{~cm}^{-1}$ could be ascribed to vibrations of M-O (M denoted to copper or iron) [19]. Also, the band that is observed around $670 \mathrm{~cm}^{-1}$ is assigned to $\left(\mathrm{Fe}_{3} \mathrm{O}_{4}\right)$ [20] [21].

\subsubsection{HRTEM}

The HRTEM micrographs in Figure $3(a, b)$ of $\mathrm{Co}-\mathrm{ZnFe}_{2} \mathrm{O}_{4}$ and $\mathrm{Cu}-\mathrm{Zn} \mathrm{Fe}_{2} \mathrm{O}_{4}$ respectively showed well-defined cubic shapes. The nano crystallites have cubic spinel structure with average diameter of $55 \mathrm{~nm}$. for the $\mathrm{Co}-\mathrm{ZnFe}_{2} \mathrm{O}_{4}$ nanoparticles and $75 \mathrm{~nm}$ for the $\mathrm{Cu}-\mathrm{ZnFe} \mathrm{O}_{4}$. The $\mathrm{Cu}-$ $\mathrm{ZnFe}_{2} \mathrm{O}_{4}$ particles showed more agglomeration where some particles formed large clusters.

\subsection{Optical properties}




\section{Reflectance and transmittance:}

Figure 4 shows the reflectance of $\mathrm{UV}$-Vis. Spectrum of $\mathrm{Co}-\mathrm{ZnFe}{ }_{2} \mathrm{O}_{4}$ and $\mathrm{Cu}-\mathrm{Zn} \mathrm{Fe}_{2} \mathrm{O}_{4}$. The fig. indicates an increase in the reflectance intensity by increasing wavelength.

Figure 5, demonstrate the reflectance intensity of the investigated nanocomposites. An increase in the PVDF reflectance were observed by the addition of nano-fillers, the largest values were spotted in case of PVDF/(Co-ZnFe2 $\left.\mathrm{O}_{4}\right)$ nanocomposite, this increase reached 5 times the PVDF original value

Figure 5 (b) shows the effect of adding the prepared nanoparticles on the transmittance of the PVDF polymer. Where the variation of the transmittance with wavelength $(\lambda)$ were investigated for pure PVDF and PVDF/ $\left(\mathrm{Co}-\mathrm{ZnFe}_{2} \mathrm{O}_{4}\right.$ and $\left.\mathrm{Cu}-\mathrm{Zn} \mathrm{Fe} \mathrm{O}_{4}\right)$ nanocomposites. It can be noted that the addition of nanoparticles lowered the transmittance values of PVDF, and the lowest vales recorded for $\mathrm{Co}-\mathrm{ZnFe} 2 \mathrm{O} 4$ nanocomposite film. This observed decrease in the nanocomposite transmittance is attributed to light scattering caused by the nanoparticles, where cobalt has higher refractive index [22] the ( $\left.\mathrm{PVDF} / \mathrm{Co}-\mathrm{ZnFe}_{2} \mathrm{O}_{4}\right)$ nanocomposite film had the lower transmittance intensity.

Moreover, Figure 6, (a) shows a remarkable increase in the PVDF absorption coefficient $(\alpha)$ with the addition of nanofillers. The absorption coefficient $(\alpha)$ of the investigated samples were obtained using the following equation [23].

$\alpha=\frac{2.303 A}{l}$

where A: absorbance, 1: thickness of the specimen.

The high absorbance values in the UV region for the investigated nanocomposite films make them of interest in UV protection applications [24], [25]. 
The extinction coefficient $(\mathrm{K})$ was calculated using the following equation [23]

$\mathrm{K}=\alpha \lambda / 4 \pi$

where, $\alpha$ and $\lambda$ are the absorption coefficient, and wavelength respectively.

The relation between the extinction coefficient $(\mathrm{K})$ and wavelength for neat PVDF and (PVDF/Co$\mathrm{ZnFe} 2 \mathrm{O} 4)$ nanocomposite is illustrated in Figure 6, (b). It is observed that (K) values increases by increase the wavelength which attributed to the interaction between the incident photons and

electrons. As well as $\mathrm{K}$ is increased by the addition of the nanofillers which may be explained by the density increase of the PVDF by addition of nanofiller.

\section{Optical bandgap:}

An atom can be moves from its normal state to an excited state as it is absorbing energy from an incident photon greater than its band gap energy. In photoexcitation an electron moves from the valence band into the conduction band across the optical band gap. The lower the energy of the band gap $\left(E_{g}\right)$, the easier for an electron to move from the valance band to the conduction band [26]. In the present work the optical band gap energy can be estimated using Tauc's relation (Tregion):

$(\alpha h v)^{n}=A\left(h v-E_{g}\right)$

where $\alpha$ is absorption coefficient, $\mathrm{A}$ is constant, $\mathrm{n}$ indicate the optical transition type ( $\mathrm{n}=2$ indicates direct transition and $\mathrm{n}=1 / 2$ indicates indirect transition) [27], [28], [29]. Figure 7 shows the relation between $(\alpha h v)^{2}$ verse the incident photon energy $(h v)$. From the linear parts of the obtained curves the direct band gap of the neat PVDF and PVDF / $\left(\mathrm{Co}-\mathrm{ZnFe}_{2} \mathrm{O}_{4}, \mathrm{Cu}-\mathrm{Zn} \mathrm{Fe} \mathrm{O}_{4},\right)$ nanocomposites have been calculated and tabulated in Table (1). It is noticed that the addition of nanoparticles, reduced the PVDF band gap to half its original value, which might be due to the creation of new levels in the PVDF band gap facilitates the movement of electrons from valance to conduction band. 
Table (1): Direct band-gap energy of PVDF and PVDF / (Co-ZnFe $\mathrm{O}_{4}, \mathrm{Cu}-\mathrm{Zn} \mathrm{Fe}_{2} \mathrm{O}_{4}$, nanocomposites

\begin{tabular}{cc}
\hline Composite & Direct bandgap (Eg.)(ev) \\
\hline PVDF & 4.45 \\
\hline PVDF / (Co-ZnFe2O4) & 2.9 \\
\hline PVDF / (Cu-ZnFe2O4) & 2.48 \\
\hline
\end{tabular}

\section{Refractive index:}

The refractive index is Another mainly important elemental property of material because of its direct relationship with the ions electronic polarizability and the local field within the material. The refractive index (n) of composite materials has been calculated via given equation [30],

$n=\frac{(1+R)}{(1-R)}+\sqrt{\frac{4 R}{(R-1)^{2}}-K^{2}}$,

where $\mathrm{R}$ is reflectance and $\mathrm{K}$ is the extinction coefficient.

Figure 8 shows the plot of the refractive index $(n)$ versus $(\lambda)$ of the samples under investigation. A remarkable increase in the refractive index value $(n)$ was observed in the PVDF by the addition of the $\mathrm{Co}-\mathrm{ZnFe} 2 \mathrm{O}_{4}$ nanoparticles. This increase can be attributed to the higher intermolecular chemical and physical interaction between the filler and the adjacent PVDF chain segments which lead an improvement of the films densities resulting in higher refractive indices and the higher refractive index [22].

\section{Optical conductivity:}

The optical conductivity $\sigma_{\text {opt. }}$ is an important parameter for studying the electronic states in materials. The optical conductivity was obtained using the following equation, [23]:

$$
\sigma_{o p t .}=\frac{\alpha n c}{4 \pi}
$$


$\alpha$ is the absorption coefficient, and $(n)$ is the refractive index of the samples.

Figure 9 illustrates the variation of optical conductivity $\sigma_{\text {opt. }}$ as a function of photon energy $h v$ for the investigated samples. It is observed that the optical conductivity of PVDF increases by the addition of nanoparticles. This increase can be attributed to the creation of new levels in the band gap which facilitates the movement of charges from valance to conduction band [31]. Co- $\mathrm{ZnFe} 2 \mathrm{O}_{4}$

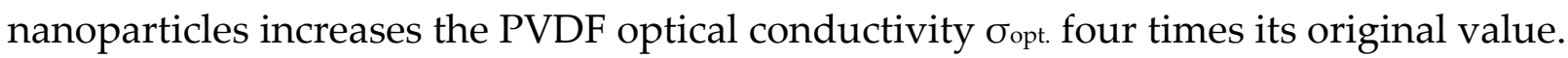

\section{Dielectric constant:}

The complex dielectric constant reveals an insight into the behavior of electrical charge carriers in materials. The real part of dielectric constant is representing the amount by which the velocity of light decreases within the material, although imaginary part of dielectric constant represents the amount of energy absorbed in the dielectric material from electric field due to dipole motion. Both the real and imaginary parts of dielectric constant have been calculated by using following expressions [23], [32] [33].

$\varepsilon_{\mathrm{r}}=\mathrm{n}^{2}-\mathrm{k}^{2}$,

$\varepsilon_{\mathrm{i}}=2 \mathrm{nk}$,

where, $\varepsilon_{\mathrm{r}}$ is real part of dielectric constant, $\varepsilon_{\mathrm{i}}$ is imaginary part of dielectric constant. The real part of dielectric constant $\left(\varepsilon_{r}\right)$ and imaginary part (dielectric loss) $\left(\varepsilon_{i}\right)$ as a function of $(h v)$ of the investigated samples shown in Figure $10(\mathrm{a}, \mathrm{b})$. It can be noted that the prepared nanoparticles (Co$\mathrm{ZnFe}_{2} \mathrm{O}_{4}$ and $\mathrm{Cu}-\mathrm{Zn} \mathrm{Fe}_{2} \mathrm{O}_{4}$ ) have improved the dielectric response of the PVDF polymer. The greater dielectric values were observed in case of $\left(\mathrm{Co}-\mathrm{ZnFe}_{2} \mathrm{O}_{4}\right)$ nanofiller where it increases the dielectric constant from 0.05 for neat PVDF to 2. These greater dielectric values resulted from the interfacial polarizations at the conductor-insulator interface [34] [35] [36]. As well as the PVDF dielectric loss increases by the addition of the nanoparticles, the higher increase was observed in the PVDF/Cu- $\mathrm{Zn} \mathrm{Fe}_{2} \mathrm{O}_{4}$ sample this increase is attributed to the increase in $n$ and $K$ with the nanofillers. 


\section{Non-linear optical (NLO) properties:}

Studying the nonlinear optics of PVDF /(Cu-Zn Fe2 $\left.\mathrm{O}_{4}\right)$ nanocomposites is helpful for the usage in several optoelectronic applications [37]. The intensity of incident light causing the occurrence of optical polarizability $\mathrm{P}$ in the nanocomposite. The nonlinear electron polarizability $\mathrm{P}_{\mathrm{NL}}$ can be obtained using the following equations: [38]

$P=\chi^{(1)} E+P_{N L}$,

$P_{N L}=\chi^{(2)} E^{2}+\chi^{(3)} E^{3}$,

where $\mathrm{E}$ is the electric field of light, $\chi^{(1)}$ is the linear optical susceptibility, $\chi^{(2)}$ is the 2nd order nonlinear optical susceptibility and $\chi^{(3)}$ is the 3rd order nonlinear optical susceptibility [39], [40], [41].

To determine the values of, $\chi^{(1)}$ and $\chi^{(3)}$ these equations can be used

$\chi^{(1)}=\frac{\left(n^{2}-1\right)}{4 \pi}$,

$\chi^{(3)}=\xi\left(\chi^{(1)}\right)^{4}$,

where $\xi=1.7 \times 10^{-10}(\mathrm{esu})$. Figure $11(\mathrm{a}, \mathrm{b})$ indicates the obtained values of $\chi^{(1)}$ and $\chi^{(3)}$ as a function of wavelength for pure PVDF and PVDF /(Co-ZnFe2 $\mathrm{O}_{4}$ and $\left.\mathrm{Cu}-\mathrm{Zn} \mathrm{Fe} \mathrm{O}_{4}\right)$ nanocomposites. For pure PVDF and PVDF /(Cu-Zn $\left.\mathrm{Fe}_{2} \mathrm{O}_{4}\right)$ nanocomposite samples, the variations of $\chi^{(1)}$ and $\chi^{(3)}$ are very small. The PVDF and PVDF /(Cu- $\left.\mathrm{Zn} \mathrm{Fe} 2 \mathrm{O}_{4}\right)$ values are almost constant and have the same pattern for both $\chi^{(1)}$ and $\chi^{(3)}$. Moreover, it is observed that the $\mathrm{Co}-\mathrm{ZnFe}_{2} \mathrm{O}_{4}$ nanofiller values of $\chi^{(3)}$ are increased and improved the nonlinear response of the PVDF polymer.

\subsection{Energy harvest performance}

Piezoelectricity is an electric polarization proportional to an applied mechanical energy or a mechanical deformation proportional to an applied electric field.

\subsubsection{Piezoelectric response using a digital storage oscilloscope (DOS)}


The working principle of the piezoelectric energy harvester of PVDF is based on the creation of an electric polarization under an applied stress [42].

The prepared nanocomposite films have been tested using a digital storage oscilloscope (DOS), where each film was placed between two copper layers electrodes. With respect to the open circuit (with forward and reverse connection), the generated piezo potential was recorded as a repetitive finger stress has been applied on the upper surface of nanocomposite films. The finger tapping generates a compressive stress on the surface of films, causes the displacement of positive and negative charges in the nanocomposite films.

It is well known that PVDF mainly have a synthetic semi crystalline polymer, and its $\beta$-phase and $\gamma$-phases are responsible for the piezoelectric power harvesting property [5].

By mechanical deformation and polarization, the structure of alpha phase can be transformed into polar beta phase to achieve piezoelectric characteristics [43].

The filler nanoparticles improved the piezo-potential as shown in Figure 12 (a-c) where an interaction between the $\mathrm{Co}-\mathrm{ZnFe} \mathrm{O}_{4}$ and $\mathrm{Cu}-\mathrm{Zn} \mathrm{Fe} \mathrm{O}_{4}$ nanoparticles and the dipoles of PVDF $\left(\mathrm{CH}_{2}=\mathrm{CF}_{2}\right)$.

This enhancement of piezo-potential in PVDF composite films is due to the role of $\mathrm{Co}-\mathrm{ZnFe} 2 \mathrm{O}_{4}$ and $\mathrm{Cu}-\mathrm{Zn} \mathrm{Fe} \mathrm{O}_{4}$ nanofillers in PVDF matrix, which is provide a conducting particle could help charge carriers induced inside the film to move to the surface. Also, the interaction between $\mathrm{Co}^{2+}, \mathrm{Zn}^{2+}$, $\mathrm{Cu}^{2+}$ and $\mathrm{Fe}^{3+}$ nanoparticles with $\mathrm{CF}_{2}$ - dipoles and $\mathrm{O}^{2-}$ nanoparticles of $\mathrm{Co}-\mathrm{ZnFe}_{2} \mathrm{O}_{4}$ and $\mathrm{Cu}-\mathrm{Zn} \mathrm{Fe} 2 \mathrm{O}_{4}$ with $\mathrm{CH}_{2}$ - dipoles could enhance the piezo response of PVDF polymer.

It can be noted that the nanofillers have enhanced the values of complex dielectric constant and the values of piezo potential of the PVDF polymer as shown in Figure $(10,12)$. That could be due to the increase in polarization causes a slight increase in the dielectric constant, where the beta phase dipoles rearranged and a transformation of alpha to beta takes place when energy is applied [44].

\subsubsection{PFM studies}


piezoresponse force microscopy (PFM) was used for measuring piezoelectric response of prepared nano samples. PFM operated in contact-mode by using an alternating voltage Va.c applied to the tip subsequent in an alternating electric field inside the specimen [45] [46]. Herein, piezoelectric samples, a periodic deformation was applied on the samples. The applied deformation causes deflection of cantilever in any directions; torsion or buckling [47]. Plane deformation (a change in the z-axis) was causing the deflection, buckling responds to an in-plane deformation (a diameter changes in the y-axis) as well as torsion is related to another in-plane deformation (a length change in the x-axis) [48]. Resolved lateral mapping of the piezoelectric behavior of the prepared sample can be obtained using PFM. The combination between PFM images of in-plane and out-of-plane which are obtained from PFM are related to domain structure [49]. The area of $2.5 \mu \mathrm{m} \times 2.5 \mu \mathrm{m}$ of the pure PVDF and $\mathrm{PVDF} /\left(\mathrm{Co}-\mathrm{ZnFe} \mathrm{O}_{4}, \mathrm{Cu}-\mathrm{ZnFe}_{2} \mathrm{O}_{4},\right)$ nanocomposite films was scanned by using Vac of $510 \mathrm{mV}$ applied to the cantilever tip. The response of PFM in the z-axis direction, phase, and amplitude micrographs of the considered samples, respectively is shown in Figure 13. The out of plane PFM phase pictures Figure 14 for all tested samples, corresponding to the piezoelectric polarization, both negative (white) and positive (black) zones showed up representing antiparallel ferroelectric nanodomains with $180^{\circ}$ domain walls [50] [51]. The white zones related to negative domains with the polarization direction perpendicular to the surface of the PVDF film and Orien situated descending, whereas the dark areas associated with positive domains having the polarization heading upward [52].

In pure PVDF, the well-defined piezoelectric spaces illustrates that the stretched crystallites are the homogeneous $\beta$-phase. The PFM amplitude for PVDF/(Co- $\mathrm{ZnFe}_{2} \mathrm{O}_{4}, \mathrm{Cu}-\mathrm{ZnFe} \mathrm{O}_{4}$, $)$ nanocomposite films (a piezoelectric contrast due to the defections caused by the applied alternating field has been noted. Therefore, the domains in the PVDF film align along the z-axis direction perpendicular to the sample and the bottom electrode, Figure 14. The in-plane PFM images Figure $13(\mathrm{~d}-\mathrm{j})$ were analyzed both for the phase and amplitude dependence of the PFM signal of PVDF/( Co-ZnFe2O4 ,Cu-ZnFe2O4) nanocomposites films. The images Figure 13, 14 
donate the formation of periodic stripe domains acquired at $\theta=0^{\circ}$. stripe domains aligned along the last saturating field direction were observed for all the pictures of $\mathrm{PVDF} /\left(\mathrm{Co}-\mathrm{ZnFe} 2 \mathrm{O}_{4}, \mathrm{Cu}-\right.$ $\mathrm{ZnFe}_{2} \mathrm{O}_{4}$ ) nanocomposites films.

\section{Conclusions}

Copper doped zinc ferrite and cobalt doped zinc ferrite nanoparticles were successfully synthesized and characterized using different characterization methods. The prepared $\mathrm{Co}-\mathrm{ZnFe} 2 \mathrm{O}_{4}$ and $\mathrm{Cu}-\mathrm{ZnFe}{ }_{2} \mathrm{O}_{4}$ nanoparticles have been used as fillers of the PVDF polymer.

The optical properties as well as piezoelectric response of pure PVDF and PVDF/(Co-ZnFe $2 \mathrm{O}_{4}$ and $\mathrm{Cu}-\mathrm{ZnFe}_{2} \mathrm{O}_{4}$ ) nanocomposites were studied. The obtained results showed a great development in the relative permittivity, optical conductivity, refractive index, and non-linear susceptibility of the $\mathrm{PVDF} /\left(\mathrm{Co}-\mathrm{ZnFe}_{2} \mathrm{O}_{4}\right)$ nanocomposite, where $\mathrm{PVDF} /\left(\mathrm{Cu}-\mathrm{ZnFe}_{2} \mathrm{O}_{4}\right)$ nanocomposite showed a lower improvement in the previous optical properties.

Both $\mathrm{PVDF} /\left(\mathrm{Co}-\mathrm{ZnFe} \mathrm{O}_{4}\right.$ and $\left.\mathrm{Cu}-\mathrm{ZnFe}_{2} \mathrm{O}_{4}\right)$ nanocomposites had lower band gap energy values than that of the pure PVDF, makes them convenient for opto-electronic applications.

The two prepared nanocomposites improved the PVDF piezoelectricity, the PVDF/(Co- $\mathrm{ZnFe} 2 \mathrm{O}_{4}$ and $\mathrm{Cu}-\mathrm{ZnFe}_{2} \mathrm{O}_{4}$ ) nanocomposites films show stripe domains aligned along the last saturating field direction when examined using PFM., the domains in the PVDF film align along the z-axis direction perpendicular to the sample and the bottom electrode.

From the obtained results, we can say that PVDF/(Co- $\left.\mathrm{ZnFe} 2 \mathrm{O}_{4}\right)$ nanocomposite is a great candidate for piezo-phototropic applications.

\section{Acknowledgment}

The authors extend their appreciation to the Institute for Research and Consulting Studies at King Khalid University through Corona Research (Fast Track). 


\section{Conflict of Interest and Authorship Conformation Form}

The authors declare that they have no known competing financial interests or personal relationships that could have appeared to influence the work reported in this paper.

\section{Manuscript title:}

Study of PVDF/ (Co-ZnFe2O4 and $\mathrm{Cu}-\mathrm{ZnFe} 2 \mathrm{O} 4)$ nanocomposite for the piezophototronics applications.

The authors whose names are listed immediately below certify that:

$\checkmark \quad$ All authors have participated in (a) conception and design, or analysis and interpretation of the data; (b) drafting the article or revising it critically for important intellectual content; and (c) approval of the final version.

$\checkmark \quad$ This manuscript has not been submitted to, nor is under review at, another journal or other publishing venue.

$\checkmark \quad$ The following authors have affiliations with organizations with direct or indirect financial interest in the subject matter discussed in the manuscript: Thebes Academy, Cairo, Egypt

Rania Ramadan $\begin{gathered}\text { Materials Science Lab. (1), Physics Department, } \\ \text { Faculty of Science, Cairo University, Giza, Egypt }\end{gathered}$




\section{References}

1. Starr, Chauncey. "Global Energy and Electricity Futures." Global Energy Demand in Transition (1995): 33-39. doi:10.1007/978-1-4899-1048-6_3.

2. Wang, Zhong Lin, Long Lin, Jun Chen, Simiao Niu, and Yunlong Zi. "Triboelectric Nanogenerators." Green Energy and Technology (2016). doi:10.1007/978-3-319-40039-6.

3. Bănică, Marian-Alin. "Energy Harvesting from Renewable Energy Sources." Lecture Notes in Networks and Systems (July 20, 2019): 247-254. doi:10.1007/978-3-030-26991-3_23.

4. Jain, Anjana, Prashanth K. J., Asheesh Kr. Sharma, Arpit Jain, and Rashmi P.N. “Dielectric and Piezoelectric Properties of PVDF/PZT Composites: A Review." Polymer Engineering \& Science 55, no. 7 (May 2, 2015): 1589-1616. doi:10.1002/pen.24088.

5. AlAhzm, Abdulrahman Mohmmed, Maan Omar Alejli, Deepalekshmi Ponnamma, Yara Elgawady, and Mariam Al Ali Al-Maadeed. "Piezoelectric Properties of Zinc Oxide/iron Oxide Filled Polyvinylidene Fluoride Nanocomposite Fibers." Journal of Materials Science: Materials in Electronics 32, no. 11 (June 2021): 14610-14622. doi:10.1007/s10854-021-060203.

6. Porter, Daniel A., Trung V.T. Hoang, and Thomas A. Berfield. “Effects of in-Situ Poling and Process Parameters on Fused Filament Fabrication Printed PVDF Sheet Mechanical and Electrical Properties." Additive Manufacturing 13 (January 2017): 81-92. doi:10.1016/j.addma.2016.11.005.

7. Yang, Lu, Jinhao Qiu, Hongli Ji, Kongjun Zhu, and Jing Wang. “Enhanced Dielectric and Ferroelectric Properties Induced by TiO2@MWCNTs Nanoparticles in Flexible Poly(vinylidene Fluoride) Composites." Composites Part A: Applied Science and Manufacturing 65 (October 2014): 125-134. doi:10.1016/j.compositesa.2014.06.006.

8. Sappati, Kiran, and Sharmistha Bhadra. "Piezoelectric Polymer and Paper Substrates: A Review." Sensors 18, no. 11 (October 24, 2018): 3605. doi:10.3390/s18113605. 
9. Sinha, Tridib Kumar, Sujoy Kumar Ghosh, Rishi Maiti, Santanu Jana, Basudam Adhikari, Dipankar Mandal, and Samit K. Ray. "Graphene-Silver-Induced Self-Polarized PVDFBased Flexible Plasmonic Nanogenerator Toward the Realization for New Class of Self Powered Optical Sensor." ACS Applied Materials \& Interfaces 8, no. 24 (June 9, 2016): 14986-14993. doi:10.1021/acsami.6b01547.

10. Wu, Wenzhuo, and Zhong Lin Wang. "Piezotronics and Piezo-Phototronics for Adaptive Electronics and Optoelectronics." Nature Reviews Materials 1, no. 7 (May 10, 2016). doi:10.1038/natrevmats.2016.31.

11. Saikh, Md. Minarul, Nur Amin Hoque, Prosenjit Biswas, Wahida Rahman, Namrata Das, Sukhen Das, and Pradip Thakur. "Self-Polarized ZrO2/Poly (vinylidene fluoride-cohexafluoropropylene) Nanocomposite-Based Piezoelectric Nanogenerator and SingleElectrode Triboelectric Nanogenerator for Sustainable Energy Harvesting from Human Movements," Physica Status Solidi (a) 218, no. 9 (March 9, 2021): 2000695. doi:10.1002/pssa.202000695.

12. Ravinder, D. “Thermoelectric Power Studies of Zinc Substituted Copper Ferrites." Journal of Alloys and Compounds 291, no. 1-2 (September 1999): 208-214. doi:10.1016/s09258388(99)00287-x.

13. Supriya, Sweety, Sunil Kumar, and Manoranjan Kar. "Band Gap Engineering of Zinc Substituted Cobalt Ferrite for Optoelectronic Applications." 2017 IEEE 12th Nanotechnology Materials and Devices Conference (NMDC) (October 2017). doi:10.1109/nmdc.2017.8350491.

14. Haponska, Monika, Anna Trojanowska, Adrianna Nogalska, Renata Jastrzab, Tania Gumi, and Bartosz Tylkowski. “PVDF Membrane Morphology-Influence of Polymer Molecular Weight and Preparation Temperature." Polymers 9, no. 12 (December 15, 2017): 718. doi:10.3390/polym9120718. 
15. Miranda, M. A. R., and J. M. Sasaki. "The Limit of Application of the Scherrer Equation." Acta Crystallographica Section A Foundations and Advances 74, no. 1 (January 1, 2018): 54-65. doi:10.1107/s2053273317014929.

16. Rana, Subhasis, John Philip, and Baldev Raj. “Micelle Based Synthesis of Cobalt Ferrite Nanoparticles and Its Characterization Using Fourier Transform Infrared Transmission Spectrometry and Thermogravimetry." Materials Chemistry and Physics 124, no. 1 (November 2010): 264-269. doi:10.1016/j.matchemphys.2010.06.029.

17. Karthickraja, D., S. Karthi, G. A. Kumar, D. K. Sardar, G. C. Dannangoda, K. S. Martirosyan, and E. K. Girija. "Fabrication of Core-shell CoFe2O4@HAp Nanoparticles: a Novel Magnetic Platform for Biomedical Applications." New Journal of Chemistry 43, no. 34 (2019): 13584-13593. doi:10.1039/c9nj02510c.

18. Ramadan, Rania. "Physical Study of Cobalt Ferrite and Its Application in Purification of Water." Applied Physics A 125, no. 12 (November 9, 2019). doi:10.1007/s00339-019-3121-8.

19. Singh, N.B., and Km Rachna. "Copper Ferrite-Polyaniline Nanocomposite and Its Application for Cr (VI) Ion Removal from Aqueous Solution." Environmental Nanotechnology, Monitoring \& Management 14 (December 2020): 100301. doi:10.1016/j.enmm.2020.100301.

20. Kamta Tedjieukeng, Hypolite Mathias, Patrice Kenfack Tsobnang, Roussin Lontio Fomekong, Ekane Peter Etape, Pattayil A. Joy, Arnaud Delcorte, and John Ngolui Lambi. "Structural Characterization and Magnetic Properties of Undoped and Copper-Doped Cobalt Ferrite Nanoparticles Prepared by the Octanoate Coprecipitation Route at Very Low Dopant Concentrations." RSC Advances 8, no. 67 (2018): 38621-38630. doi:10.1039/c8ra08532c.

21. Kirankumar, Venkat Savunthari, and Shanmugam Sumathi. "Photocatalytic and Antibacterial Activity of Bismuth and Copper Co-Doped Cobalt Ferrite Nanoparticles." 
Journal of Materials Science: Materials in Electronics 29, no. 10 (March 14, 2018): 8738-8746. doi:10.1007/s10854-018-8890-x.

22. Habubi, N. F., K. A. Mishjil, and S. S. Chiad. "Structural Properties and Refractive Index Dispersion of Cobalt Doped SnO2 Thin Films." Indian Journal of Physics 87, no. 3 (November 25, 2012): 235-239. doi:10.1007/s12648-012-0223-y.

23. Vasudeo Rane, Ajay, Sabu Thomas, and Nandakumar Kalarikkal, eds. "Microscopy Applied to Materials Sciences and Life Sciences" (November 21, 2018). doi:10.1201/9781351251587.

24. Abd-Elsalam, Kamel A., and Ram Prasad, eds. "Nanobiotechnology Applications in Plant Protection." Nanotechnology in the Life Sciences (2019). doi:10.1007/978-3-030-13296-5.

25. Ismail, A.M., M.I. Mohammed, and S.S. Fouad. "Optical and Structural Properties of Polyvinylidene Fluoride (PVDF) / Reduced Graphene Oxide (RGO) Nanocomposites." Journal of Molecular Structure 1170 (October 2018): 51-59. doi:10.1016/j.molstruc.2018.05.083.

26. Li, Zhongwen, Rui-Juan Xiao, Peng Xu, Chunhui Zhu, Shuaishuai Sun, Dingguo Zheng, Hong Wang, et al. “Lattice Dynamics and Contraction of Energy Bandgap in Photoexcited Semiconducting Boron Nitride Nanotubes." ACS Nano 13, no. 10 (September 18, 2019): 11623-11631. doi:10.1021/acsnano.9b05466.

27. Jubu, P.R., F.K. Yam, V.M. Igba, and K.P. Beh. “Tauc-Plot Scale and Extrapolation Effect on Bandgap Estimation from UV-vis-NIR Data - A Case Study of $\beta$-Ga2O3." Journal of SolidState Chemistry 290 (October 2020): 121576. doi:10.1016/j.jssc.2020.121576.

28. Rafferty, B., and L. M. Brown. "Direct and Indirect Transitions in the Region of the Band Gap Using Electron-Energy-Loss Spectroscopy." Physical Review B 58, no. 16 (October 15, 1998): 10326-10337. doi:10.1103/physrevb.58.10326.

29. Soukoulis, C. M. “Photonic Band Gap Materials.” Diffuse Waves in Complex Media (1999): 93-107. doi:10.1007/978-94-011-4572-5_4. 
30. Bhagat, D.J., and G.R. Dhokane. "UV-VIS Spectroscopic Studies of One Pot Chemically Synthesized Polyindole/poly(vinyl Acetate) Composite Films." Materials Letters 136 (December 2014): 251-253. doi:10.1016/j.matlet.2014.08.003.

31. Kokhanovsky, Alexander A., ed. "Light Scattering Reviews 2." Springer Praxis Books (2007). doi:10.1007/978-3-540-68435-0.

32. Cho, Y.S., and K.H. Yoon. "Dielectric Ceramics." Handbook of Advanced Electronic and Photonic Materials and Devices (2001): 175-199. doi:10.1016/b978-012513745-4/50040-8.

33. Stoller, Patrick, Volker Jacobsen, and Vahid Sandoghdar. "Measurement of the Complex Dielectric Constant of a Single Gold Nanoparticle." Optics Letters 31, no. 16 (July 25, 2006): 2474. doi:10.1364/ol.31.002474.

34. Kim, Jin-Young, TaeYoung Kim, Ji Won Suk, Harry Chou, Ji-Hoon Jang, Jong Ho Lee, Iskandar N. Kholmanov, Deji Akinwande, and Rodney S. Ruoff. "Enhanced Dielectric Performance in Polymer Composite Films with Carbon Nanotube-Reduced Graphene Oxide Hybrid Filler." Small 10, no. 16 (May 2, 2014): 3405-3411. doi:10.1002/smll.201400363.

35. Klyukin, Konstantin, and Vitaly Alexandrov. "Effect of Intrinsic Point Defects on Ferroelectric Polarization Behavior of SrTiO3." Physical Review B 95, no. 3 (January 4, 2017). doi:10.1103/physrevb.95.035301.

36. Hadi, Muhammad, Khalid Mujasam Batoo, Ankush Chauhan, Omar M. Aldossary, Ritesh Verma, and Yujie Yang. "Tuning of Structural, Dielectric, and Electronic Properties of $\mathrm{Cu}$ Doped Co-Zn Ferrite Nanoparticles for Multilayer Inductor Chip Applications." Magnetochemistry 7, no. 4 (April 14, 2021): 53. doi:10.3390/magnetochemistry7040053.

37. Zahran, H.Y., I.S. Yahia, and F.H. Alamri. “Nanostructured Pyronin Y Thin Films as a New Organic Semiconductor: Linear/nonlinear Optics, Band Gap and Dielectric Properties." Physica B: Condensed Matter 513 (May 2017): 95-102. doi:10.1016/j.physb.2017.02.026. 
38. Yahia, I.S., G.F. Salem, Javed Iqbal, and F. Yakuphanoglu. “Linear and Nonlinear Optical Discussions of Nanostructured Zn-Doped CdO Thin Films." Physica B: Condensed Matter 511 (April 2017): 54-60. doi:10.1016/j.physb.2017.01.030.

39. Shkir, Mohd., V. Ganesh, S. AlFaify, and I. S. Yahia. "Structural, Linear and Third Order Nonlinear Optical Properties of Drop Casting Deposited High Quality Nanocrystalline Phenol Red Thin Films." Journal of Materials Science: Materials in Electronics 28, no. 14 (April 4, 2017): 10573-10581. doi:10.1007/s10854-017-6831-8.

40. Tichý, Miloš, Jana Tichá, and Michal Kočer. Earth, Moon, and Planets 90, no. 1/4 (2002): 507-513. doi:10.1023/a:1021571425439.

41. Yahia, I.S., H.Y. Zahran, and F.H. Alamri. "Linear and Nonlinear Optics of Pyronin Y/flexible Polymer Substrate for Flexible Organic Technology: New Optical Approach." Optics \& Laser Technology 95 (October 2017): 124-132. doi:10.1016/j.optlastec.2017.03.047.

42. Jana, Santanu, Samiran Garain, Shrabanee Sen, and Dipankar Mandal. "The Influence of Hydrogen Bonding on the Dielectric Constant and the Piezoelectric Energy Harvesting Performance of Hydrated Metal Salt Mediated PVDF Films." Physical Chemistry Chemical Physics 17, no. 26 (2015): 17429-17436. doi:10.1039/c5cp01820j.

43. Mohammadi, Behzad, Ali Akbar Yousefi, and Samad Moemen Bellah. "Effect of Tensile Strain Rate and Elongation on Crystalline Structure and Piezoelectric Properties of PVDF Thin Films." Polymer Testing 26, no. 1 (February 2007): 42-50. doi:10.1016/j.polymertesting.2006.08.003.

44. Fu, Jing, Yudong Hou, Mupeng Zheng, Qiaoyi Wei, Mankang Zhu, and Hui Yan. “Improving Dielectric Properties of PVDF Composites by Employing Surface Modified Strong Polarized BaTiO3 Particles Derived by Molten Salt Method." ACS Applied Materials \& Interfaces 7, no. 44 (October 29, 2015): 24480-24491. doi:10.1021/acsami.5b05344. 
45. Liu, Huicong, Junwen Zhong, Chengkuo Lee, Seung-Wuk Lee, and Liwei Lin. "A Comprehensive Review on Piezoelectric Energy Harvesting Technology: Materials, Mechanisms, and Applications." Applied Physics Reviews 5, no. 4 (December 2018): 041306. doi:10.1063/1.5074184.

46. Fortunato, Marco, Hossein Cheraghi Bidsorkhi, Chandrakanth Reddy Chandraiahgari, Giovanni De Bellis, Francesca Sarto, and Maria Sabrina Sarto. "PFM Characterization of PVDF Nanocomposite Films With Enhanced Piezoelectric Response." IEEE Transactions on Nanotechnology 17, no. 5 (September 2018): 955-961. doi:10.1109/tnano.2018.2833201.

47. Vasileva, Daria, Semen Vasilev, Andrei L. Kholkin, and Vladimir Ya. Shur. "Domain Diversity and Polarization Switching in Amino Acid $\beta$-Glycine." Materials 12, no. 8 (April 15, 2019): 1223. doi:10.3390/ma12081223.

48. Mahadeva, Suresha K, John Berring, Konrad Walus, and Boris Stoeber. “Effect of Poling Time and Grid Voltage on Phase Transition and Piezoelectricity of Poly(vinyledene Fluoride) Thin Films Using Corona Poling." Journal of Physics D: Applied Physics 46, no. 28 (June 25, 2013): 285305. doi:10.1088/0022-3727/46/28/285305.

49. Liu, Xia, Sixing $\mathrm{Xu}$, Xuanlin Kuang, Daxin Tan, and Xiaohong Wang. "Nanoscale Investigations on $\beta$-Phase Orientation, Piezoelectric Response, and Polarization Direction of Electrospun PVDF Nanofibers." RSC Advances 6, no. 110 (2016): 109061-109066. doi:10.1039/c6ra24473d.

50. Damjanovic, Dragan. "Hysteresis in Piezoelectric and Ferroelectric Materials." The Science of Hysteresis (2006): 337-465. doi:10.1016/b978-012480874-4/50022-1.

51. Nakhmanson, S. M., M. Buongiorno Nardelli, and J. Bernholc. "Ab InitioStudies of Polarization and Piezoelectricity in Vinylidene Fluoride and BN-Based Polymers." Physical Review Letters 92, no. 11 (March 18, 2004). doi:10.1103/physrevlett.92.115504.

52. Chen, Deyang, Zuhuang Chen, Qian He, James D. Clarkson, Claudy R. Serrao, Ajay K. Yadav, Mark E. Nowakowski, et al. “Interface Engineering of Domain Structures in BiFeO3 
Thin Films." Nano Letters 17, no. 1 (December 9, 2016): 486-493. doi:10.1021/acs.nanolett.6b04512. 
Figures

\section{Figure 1}

XRD pattern of $\mathrm{CoFe}_{2} \mathrm{O}_{4}, \mathrm{CuFe}_{2} \mathrm{O}_{4}$ and $\mathrm{Cu}-\mathrm{CoFe}_{2} \mathrm{O}_{4}$ nanoparticles.

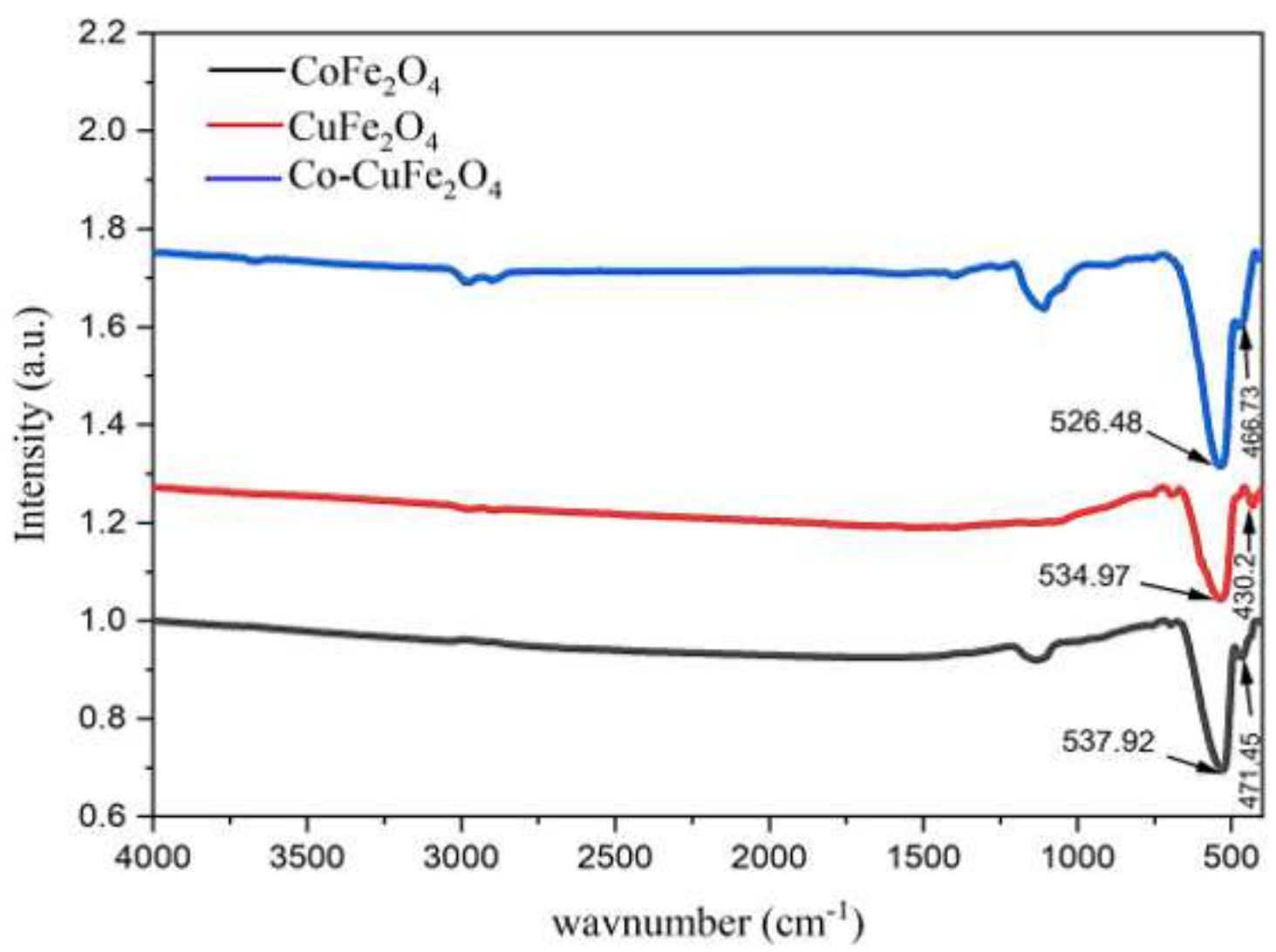

Figure 2

FTIR spectrum of $\mathrm{CoFe}_{2} \mathrm{O}_{4}, \mathrm{CuFe}_{2} \mathrm{O}_{4}$ and $\mathrm{Cu}-\mathrm{CoFe}_{2} \mathrm{O}_{4}$ nanoparticles.

\section{Figure 3}

a,b and c): FESEM micrographs of $\mathrm{CoFe}_{2} \mathrm{O}_{4}, \mathrm{CuFe}_{2} \mathrm{O}_{4}$ and $\mathrm{Cu}-\mathrm{CoFe}_{2} \mathrm{O}_{4}$ nanoparticles

Figure 4

Reflectance of UV-Vis. spectrum of $\mathrm{CoFe}_{2} \mathrm{O}_{4}, \mathrm{CuFe}_{2} \mathrm{O}_{4}$ and $\mathrm{Cu}-\mathrm{CoFe}_{2} \mathrm{O}_{4}$ 


\section{Figure 5}

a, b): (a) Reflectance of UV-Vis. Spectrum of PVDF/(Cu-CoFe $\mathrm{O}_{4}, \mathrm{CoFe}_{2} \mathrm{O}_{4}$, and $\left.\mathrm{CuFe}_{2} \mathrm{O}_{4}\right)$, (b) Transmittance of UV-Vis. Spectrum of PVDF/(Cu-CoFe $\mathrm{O}_{4}, \mathrm{CoFe}_{2} \mathrm{O}_{4}$, and $\left.\mathrm{CuFe}_{2} \mathrm{O}_{4}\right)$

\section{Figure 6}

a, b): (a) Absorption coefficient of PVDF/(Cu-CoFe $\mathrm{O}_{4}, \mathrm{CoFe}_{2} \mathrm{O}_{4}$, and $\left.\mathrm{CuFe}_{2} \mathrm{O}_{4}\right)$, (b) Extinction coefficient of PVDF/(Cu-CoFe $\mathrm{O}_{4}, \mathrm{CoFe}_{2} \mathrm{O}_{4}$, and $\mathrm{CuFe}_{2} \mathrm{O}_{4}$

Figure 7

Refractive index of PVDF/(Cu-CoFe $\mathrm{O}_{4}, \mathrm{CoFe}_{2} \mathrm{O}_{4}$, and $\left.\mathrm{CuFe}_{2} \mathrm{O}_{4}\right)$,

\section{Figure 8}

Optical conductivity of PVDF/(Cu-CoFe $\mathrm{O}_{4}, \mathrm{CoFe}_{2} \mathrm{O}_{4}$, and $\mathrm{CuFe}_{2} \mathrm{O}_{4}$

\section{Figure 9}

a-h): (a-d) Real dielectric constant of PVDF/(Cu-CoFe $\mathrm{O}_{4}, \mathrm{CoFe}_{2} \mathrm{O}_{4}$, and $\left.\mathrm{CuFe}_{2} \mathrm{O}_{4}\right)$, (e-h) Imaginary dielectric constant of PVDF/(Cu-CoFe $\mathrm{O}_{4}, \mathrm{CoFe}_{2} \mathrm{O}_{4}$, and $\left.\mathrm{CuFe}_{2} \mathrm{O}_{4}\right)$

\section{Figure 10}

a-d): Open-circuit output voltages from PVDF/(Cu-CoFe $\mathrm{O}_{4}, \mathrm{CoFe}_{2} \mathrm{O}_{4}$, and $\left.\mathrm{CuFe}_{2} \mathrm{O}_{4}\right)$ nanocomposite films during repetitive impact by a human's finger.

\section{Figure 11}


a-I): Z-axis direction, phase and amplitude PFM micrographs of PVDF/(Cu-CoFe $\mathrm{O}_{4}, \mathrm{CoFe}_{2} \mathrm{O}_{4}$, and $\mathrm{CuFe}_{2} \mathrm{O}_{4}$ ) nanocomposite films.

\section{Figure 13}

Figures 13-14 not available with this version.

\section{Supplementary Files}

This is a list of supplementary files associated with this preprint. Click to download.

- graphicalabstract2.jpg 